\title{
edmetic
}

Revista de Educación Mediática y TIC

\section{Antecedentes, estado de la cuestión y prospectiva de las Radios Universitarias}

Las radios universitarias en España son un fenómeno relativamente reciente, ya que en nuestro país comenzaron a desarrollarse de forma tardía si se compara con lo que sucedió en otros lugares como Estados Unidos o en países del entorno iberoamericano, donde estados como Argentina o Colombia, van muchos pasos por delante. En nuestro caso, esta tipología de emisoras cuenta con una trayectoria marcada por un desarrollo lento y pausado al principio, y por una eclosión, cuasi geométrica, en estos últimos años, al amparo de la evolución continua de las tecnologías de la información y la comunicación (Marta-Lazo y Segura-Anaya, 2012: 104-106).

Los orígenes de estas emisoras han de buscarse en las radios educativas, que tanto éxito han tenido en nuestro entorno desde mediados de siglo pasado, creciendo en escuelas y centros educativos, preocupados por la motivación de su alumnado, y por una forma distinta del proceder didáctico, produciendo frutos considerables en la formación integral de los estudiantes. Como no podía ser de otra manera, este tipo de radio, gracias al impulso adquirido, dio el salto a las instituciones de educación superior, debemos situar nuestra mirada en los años setenta y ochenta y dirigirla hacia el caso particular de Radio UNED, la emisora de radio de la Universidad Nacional de Educación a distancia, y a Radio San Fernando (actualmente, Radio Campus), la emisora de la Universidad de La Laguna; ambas experiencias son las precursoras que inician este tipo de radiodifusión en nuestro país, pero no será hasta inicios del nuevo siglo cuando este movimiento radiofónico alcance su culmen. Teniendo en cuenta estos datos iniciales podemos dividir este fenómeno en tres fases

edmetic, 3(1), 2014, E-ISSN: 2254-0059; pp. 3-8 
completamente diferenciadas (Martín, 2013: 120-140):

- Fase 1 (último cuarto de siglo XX): esta fase está marcada por la aparición del fenómeno y las primeras experiencias, como hemos comentado, nos encontramos ante un desarrollo tardío, lento y pausado. Además de las experiencias iniciales, ya mencionadas, destacan la aparición de Radio Complutense, Radio Universidad de Salamanca o la 98.3 Radio, todas ellas en la última década del siglo pasado.

- Fase 2 (primera década del siglo XXI): en estos años asistimos a la consolidación y expansión del fenómeno, que vive un auténtico boom ya que en poco más de diez años surgen en torno a la quincena de estaciones, gracias sobre todo a la evolución y uso de las TICs por parte de las emisoras, a la consolidación de las radios universitarias como plataformas prácticas para el alumnado del área de ciencias de la información y al paulatino acercamiento a la sociedad.

- Fase 3 (actualmente en desarrollo): este periodo está marcado por la crisis económica que afecta a la sociedad española, en general, y a la universidad, en particular. Nos encontramos ante una fase de replanteamiento y unión del fenómeno, que queda plasmada en 2011, con la creación de la Asociación de Radios Universitarias de España (ARU) durante la celebración del séptimo encuentro celebrado en junio de 2011 en Badajoz (Universidad de Extremadura). En estos últimos años, han surgido apenas 3 emisoras, todas ellas en universidades con estudios de comunicación, bajo el amparo y desarrollo de las TIC y en forma de plataformas hipermedias, que permiten la formación integral del alumnado de la rama de las ciencias de la información.

edmetic, 3(1), 2014, E-ISSN: 2254-0059; pp.2-7 
Las realidades de este tipo de estaciones, en cuanto a su origen y su modelo, son muy diversas. Hay radios que se crean por las universidades para proporcionar a los alumnos unas prácticas más profesionales como complementos de su formación teórica, o emisoras que se ponen en marcha gracias a un movimiento estudiantil, o estaciones que surgen como iniciativa directa de los órganos de gobierno buscando una comunicación externa e interna más efectiva, así como una mejora de su imagen e identidad. Sea de una manera o de otra, el apoyo del equipo de gobierno es fundamental, como queda patente actualmente con el caso de UniRadio Huelva, que está viviendo momentos complicadas debido a un cambio de equipo rectoral.

Otro punto que ha provocado la expansión de este tipo de radios, sin lugar a dudas, son las tecnologías de la información y la comunicación, ya que han venido a facilitar la vida a estas estaciones, tanto en el tema legal, como espacial o temporal. Uno de los principales problemas existentes, es conseguir licencias administrativas para la emisión, las radios universitarias tienen ese campo minado y de difícil acceso, y gracias a Internet, pueden salir al aire con todas las garantías, supliendo esa carencia e, incluso, pudiendo alcanzar una repercusión mayor, al romper las barreras espacio-temporales; los servicios de podcast, la radio a la carta, las aplicaciones para teléfonos inteligentes, los servicios interactivos y de democratización del medio han venido a consolidar el papel de servicio público y social de estas emisoras, no sólo en el ámbito académico, sino en el ámbito exterior a la institución, dando la voz a la sociedad, que otros medios le niegan.

En definitiva, nos encontramos en un momento idóneo, a pesar de la crisis reinante, para emprender un proyecto radiofónico universitario, en comparación con unos años atrás, y todo ello gracias a los avances en las tecnologías y al apoyo de la ARU, que han facilitado el proceso de inicio de la aventura radiofónica universitaria. Internet o el Software Libre, sólo son unos

edmetic, 3(1), 2014, E-ISSN: 2254-0059; pp. 3-8 
ejemplos de la facilidad legal y económica que impera en la actualidad. Nos encontramos en un escenario de innovaciones continuas, un entorno en el que se nos ofrecen interesantes oportunidades para la evolución de este tipo de estaciones, únicamente limitadas, en la actualidad, por las circunstancias económicas que rodean al país, en general, y a la Universidad, en particular.

Un momento idóneo, también para la publicación de este monográfico que realiza una aproximación muy certera al fenómeno. Los artículos que presentamos abarcan los siguientes contenidos:

Carmen Marta-Lazo y Daniel Martín Pena realizan una contextualización panorámica del objeto de estudio del monográfico. Bajo el título "Investigación sobre radio universitaria: Presente, pasado y futuro" compilan cuáles son los fundamentos de esta línea de análisis que apenas viene desarrollándose desde hace unos años en nuestro país, fruto del despliegue que han llevado a cabo en los últimos años las diferentes estaciones y portales de radio instalados en las diferentes universidades españolas, a lo que se suma la potencialidad del asociacionismo entre ellas para llevar a cabo investigaciones en común como la que nos ocupa.

Cinta Espino, a través del artículo "Contenidos, estructura, y función social en la programación de las radios universitarias de España", nos acerca una radiografía de las características de las radios universitarias en nuestro país, para ello la autora parte del análisis de las propuestas programáticas de las emisoras universitarias españolas. Como no puede ser de otra manera, la divulgación del conocimiento es una de las piedras angulares de estas radios, como queda patente en el artículo de Ana Segura "Divulgación científica en las radios universitarias españolas", en el cual plantea la modalidad de contenidos y formatos que se emiten en este tipo de emisoras y se adentra en los espacios especializados en divulgación de la ciencia.

Miguel Ángel Ortiz- Sobrino, Dolores Rodríguez-Barba y Jean Jacques Cheval proponen en su artículo, "La radio universitaria en el Siglo XXI: Perspectiva Hispano Francesa", desde un enfoque histórico, un análisis 
comparativo de la trayectoria que ha seguido el desarrollo de las emisoras universitarias en Francia y en España.

Lucia Casajús y Marina Vázquez analizan en su artículo "Los jóvenes prosumidores en la radio universitaria 2.0: un perfil en construcción" el perfil del prosumidor en la radio universitaria 2.0, reflejando la importancia que tienen en las emisoras todo lo relacionado con las TIC.

Los programas son el núcleo de las emisoras, por ello la programación y los objetivos de las mismas, así como el marcado perfil social de este tipo de estaciones son motivo de análisis para Paloma Contreras, Manvel GonzálezMairena y José Ignacio Aguaded en su artículo "Programar una radio social en la universidad: el Propósito Penélope de UniRadio".

Hemos comentado que el trabajo en asociado o en red debe ser el punto fuerte de las radios universitarias en unos momentos tan complicados como los actuales, es por ello que Tiziana Cavallo y Guillermo Gaviria tratan en su artículo "Radio universitaria: Trabajo en red como imperativo", este trabajo asociativo desde un prisma internacional, reflejando el papel decisivo de las redes colaborativas como concepto clave en la filosofía de las emisoras universitarias, tanto desde el punto de vista individual como del colectivo.

Nos encontramos ante un completo y documentado análisis del fenómeno de las radios universitarias, que va más allá de la realidad que se vive en nuestro país.

Carmen Marta-Lazo

Universidad de Zaragoza

Daniel Martín Pena

Universidad de Extremadura

\section{Referencias bibliográficas:}

MARTA-LAZO, C. y SEGURA-ANAYA, A. (2012). Emisoras universitarias españolas en la Web 3.0: programación y contenidos. (pp. 103-124). En C. Espino Narváez y D. Martín Pena (eds.) (2012). Las radios universitarias, más allá 
de la radio. Las TIC como recursos de interacción radiofónica. Barcelona: Editorial UOC,

MARTÍN PENA, D. (2013). Radios universitarias en España: plataformas de comunicación interactiva y redes de colaboración. Tesis doctoral. Universidad de Huelva. 